\title{
The impact of admission blood glucose level on patients with community-acquired pneumonia
}

Tamer M. Ali, Hala M. Salem, Dina R. Sultan

\begin{abstract}
Background Pneumonia is one of the most common diseases with a high hospitalization rate. Many studies have suggested that there is a correlation between pre-existing diabetes and the alterations in serum glucose levels in patients with community-acquired pneumonia (CAP) and high death rate.
\end{abstract}

Aim To study the impact of admission blood glucose level on patients' outcomes with CAP.

Patients and methods Sixty (30 nondiabetic and 30 diabetic patients) consecutive hospitalized adult patients with CAP were recruited over a 1-year period. Data on patients' outcomes including duration of hospital stay, duration of antibiotic treatment, increase in oxygen requirements, increase in antibiotics coverage, ICU admission, mechanical ventilation, and in-hospital mortality were collected.

Results Admission blood glucose level was elevated in diabetic patients (the mean plasma glucose level was 258.86 $\pm 116.15 \mathrm{mg} / \mathrm{dl}$ in diabetics and $151.13 \pm 51.23 \mathrm{mg} / \mathrm{dl}$ in nondiabetics). There were statistically significant increases in the duration of hospital stay $(7.633 \pm 3.567$ nondiabetic vs. $11.267 \pm 4.291$ diabetic patients in days), duration of antibiotic treatment $(7.633 \pm 3.567$ nondiabetic vs. $11.267 \pm 4.291$ diabetic patients in days), increase in $\mathrm{O}_{2}$ requirements (33.33

\section{Introduction}

Community-acquired pneumonia (CAP) is a common disease that leads to significant morbidity and mortality, and its annual incidence varies from 5 to $11 / 1000$ population; $20 \%$ of these patients require hospitalization, which places a significant economic burden on the society [1].

Hyperglycemia has a major influence on the function of the immune system; it combines in-vitro with ingredients of the innate immune system [2] and also combines with the adaptive immune system, causing direct inhibition of T-lymphocyte, immunoglobulin, and complement functions [3].

Hyperglycemia can occur because of diabetes mellitus or stress. Stress induced by hyperglycemia resulted from increase in catecholamine, growth hormone, glucagon, proinflammatory cytokines [4].

Hyperglycemia on admission is considered an absolute risk factor for higher complication rates and higher mortality in patients with CAP with or without diabetes [5]. Most studies have found that there is an association between hyperglycemia and long-term mortality after each CAP episode [6]. Thus, it is crucial vs. $70 \%$ ), increase in antibiotics coverage (16.67 vs. $63.33 \%)$, and ICU admission (30 vs. 63.33\%) in the diabetic group on comparing nondiabetic versus diabetic patients with CAP. Also, the previously mentioned outcomes increased significantly with increasing blood glucose levels among the entire study population.

Conclusion On admission, CAP patients with increased blood glucose level, either diabetic or nondiabetic, are expected to have poor outcomes.

Egypt J Bronchol 2019 13:551-555

(C) 2019 Egyptian Journal of Bronchology

Egyptian Journal of Bronchology 2019 13:551-555

Keywords: antibiotics, blood glucose, community-acquired pneumonia, hospital stay, hyperglycemia

Department of Chest Diseases, Faculty of Medicine, Ain Shams University, Cairo, Egypt

Correspondence to Dina R. Sultan, MD, Lecturer of Chest Medicine in Faculty of Medicine in Ain Shams University, 38 Abbasia Next Nour Mosque, Cairo, 11517, Egypt. Tel: +20 110208 4652; e-mail: drdinaruby2020@gmail.com

Received: 14 July 2019 Revised: 26 July 2019 Accepted: 10 September 2019 Published: 25 October 2019

to study the impact of admission blood glucose levels on outcomes in patients with CAP in our hospital.

\section{Patients and methods}

\section{Study design and setting}

This prospective study was carried out at the Chest Department, Ain Shams University Hospitals from January 2018 to January 2019 after approval by the Ethics Committee of the Chest Department and on obtaining verbal informed consent from all patients.

\section{Study sample}

Sixty consecutive adult patients ( $>18$ years) admitted for at least $24 \mathrm{~h}$ in the ward during the study with CAP (symptoms of cough, purulent expectoration, fever, a new abnormality on chest radiograph with no recent hospital admission) were recruited by convenience sampling. The diagnosis of CAP was made on the basis of ATS/IDSA guidelines [7]; the patients were

This is an open access journal, and articles are distributed under the terms of the Creative Commons Attribution-NonCommercial-ShareAlike 4.0 License, which allows others to remix, tweak, and build upon the work non-commercially, as long as appropriate credit is given and the new creations are licensed under the identical terms. 
divided according to information collected about diabetes into 30 nondiabetic patients and 30 diabetic patients (diabetes was defined as a doctor's diagnosis that had been made before the current pneumonia episode, and verified from the patient files, or if the patient was receiving medication for diabetes).

Patients with aspiration pneumonia, those who had already received antibiotic treatment before admission, patients with recent tuberculosis infection, patients under treatment with corticosteroids $(\geq 20 \mathrm{mg}$ prednisolone-equivalent/day $>14$ days), immunocompromised patients (HIV infection, receiving chemotherapy in the last month before inclusion in the study), pregnant women, and patients admitted in the ward less than $24 \mathrm{~h}$ were excluded.

\section{Study tool}

All patients selected in the study were subjected to a full assessment of medical history (age, sex, smoking status, comorbidities, and history of recent hospital admission and history of drug intake), complete clinical examination, radiological investigations [chest $\mathrm{x}$ ray $(\mathrm{CXR})$ posterior anterior (PA) view and computed tomography (CT) chest whenever needed], laboratory investigations, arterial blood gases on room air, and bacteriological investigations (sputum culture, sputum Ziehl-Neelsen); the CURB-65 score on admission was used to assess CAP severity as stated previously in the literature [8].

Blood glucose level on admission was measured in both groups using an Accu-chek blood glucose meter model (Accu-chek Active) manufactured by Roche Diabetes Care (Basel, Switzerland) (after washing our hands, the test strip was inserted into the device and we placed the device on the side of the patient's fingertip to obtain the blood sample; then touching and holding the edge of the test strip to the drop of blood then the result appeared) [9].

Data related to hospitalization were collected, included duration of hospital stay, duration of antibiotic coverage, and complications such as increase in oxygen $\left(\mathrm{O}_{2}\right)$ requirement, increase antibiotic coverage (defined as increase the dose and/or the number of antibiotics than that prescribed on admission), sepsis, admission to the ICU with or without mechanical ventilation, and in-hospital mortality.

\section{Statistical analysis}

Quantitative variables were presented as mean and SD, comparison between two means was performed using the independent $t$-test. Categorical data were presented as count and percentages. Comparison between proportions was performed using the $\chi^{2}-$ test. The analysis of variance (ANOVA) test was used to compare more than two groups as regard quantitative variables. $P$ values equal to or less than 0.05 were considered statistically significant. SPSS version 20 (IBM, American Multinational Information Technology Company, Armonk, New York) was used for data analysis.

\section{Results}

The majority of the studied population included men; 73.33 and $53.33 \%$ of the patients in the nondiabetic and the diabetic group, respectively, were men, with a mean age 60 years among nondiabetics and 62 years among diabetics. There were no statistically significant differences between nondiabetic and diabetic patients in the sociodemographic data and comorbidities in Table 1.

Table 1 Demographic data and comorbidities in both nondiabetic and diabetic patients

\begin{tabular}{|c|c|c|c|}
\hline & \multicolumn{2}{|c|}{ Groups } & \multirow{2}{*}{$\begin{array}{c}t \text {-Test or } \chi^{2} \\
P \text { value }\end{array}$} \\
\hline & Nondiabetic & Diabetic & \\
\hline Age (mean $\pm S D)$ (years) & $60.300 \pm 18.859$ & $62.067 \pm 12.868$ & 0.673 \\
\hline \multicolumn{4}{|l|}{$\operatorname{Sex}[n(\%)]$} \\
\hline Male & $22(73.33)$ & $16(53.33)$ & 0.108 \\
\hline Female & $8(26.67)$ & $14(46.67)$ & \\
\hline Pack/year $($ mean $\pm S D)$ & $32.737 \pm 15.726$ & $30.000 \pm 19.640$ & 0.655 \\
\hline \multicolumn{4}{|l|}{ Comorbidities $[n(\%)]$} \\
\hline Pulmonary disease & $6(20)$ & $11(36.67)$ & 0.152 \\
\hline Cardiac disease & $6(20)$ & $9(30)$ & 0.371 \\
\hline Liver disease & $3(10)$ & 0 & 0.076 \\
\hline Malignancy & $2(6.67)$ & $3(10)$ & 0.640 \\
\hline Chronic renal disease & $2(6.67)$ & $5(16.67)$ & 0.228 \\
\hline Neurological disease & $3(10)$ & $5(16.67)$ & 0.448 \\
\hline
\end{tabular}


In Table 2, the mean plasma glucose level on admission was elevated in diabetics in comparison with nondiabetics as the mean blood glucose level was $258.867 \pm 116.154 \mathrm{mg} / \mathrm{dl}$ in diabetics and 151.133 $\pm 51.235 \mathrm{mg} / \mathrm{dl}$ in nondiabetics. Also, on classifying blood glucose, it was found that the majority of nondiabetics (76.6\%) had blood glucose levels ranging from 110 to $199 \mathrm{mg} / \mathrm{dl}$, whereas in more than half the diabetic patients, the blood glucose level was above $250 \mathrm{mg} / \mathrm{dl}$; thus, there was a statistically significant difference between nondiabetic and diabetic patients.

There was no statistically significant difference between both groups in the different parameters of the CURB-65 score (Table 3).

There was no statistically significant difference between nondiabetics and diabetics in the arterial blood gas parameters [potential hydrogen $(\mathrm{PH})$, $\mathrm{PaO}_{2}$ : partial pressure of oxygen in arterial blood and oxygen saturation; $P$ values were $0.434,0.878$, and 0.896 , respectively].

There were statistically significant increases in the duration of hospital stay $(7.633 \pm 3.567$ nondiabetic vs. 11.267 \pm 4.291 diabetic patients in days), duration of antibiotic treatment $(7.633 \pm 3.567$ nondiabetic vs. $11.267 \pm 4.291$ diabetic patients in days), increase in $\mathrm{O}_{2}$ requirements (33.33 vs. $70 \%)$, increase antibiotics coverage (16.67 vs. $63.33 \%$ ), and ICU admission (30 vs. $63.33 \%$ ) among the diabetic group on comparing nondiabetic versus diabetic patients with CAP. However, there was no statistically significant difference between nondiabetic and diabetic patients with CAP in terms of sepsis, mechanical ventilation, and in-hospital mortality (Table 4).

On comparing between the different admission blood glucose levels in the entire study population (nondiabetic and diabetic patients) and outcomes of CAP patients, there was a statistically significant increase in the duration of hospital stay $(13.211 \pm 3.614$ days $)$,

Table 2 Glucose levels at admission in nondiabetic and diabetic patients

\begin{tabular}{|c|c|c|c|}
\hline & \multicolumn{2}{|c|}{ Groups } & \multirow{2}{*}{$\begin{array}{c}t \text {-Test or } \chi^{2} \\
P \text { value }\end{array}$} \\
\hline & Nondiabetic & Diabetic & \\
\hline \multicolumn{4}{|c|}{ Glucose level at admission } \\
\hline Mean \pm SD & $151.133 \pm 51.235$ & $258.867 \pm 116.154$ & $<0.001^{\star \star}$ \\
\hline$<110 \mathrm{mg} / \mathrm{dl}$ & 1 (3.33) & $3(10.00)$ & $<0.001^{\star *}$ \\
\hline $110-199 \mathrm{mg} / \mathrm{dl}$ & $23(76.67)$ & $8(26.67)$ & \\
\hline $200-250 \mathrm{mg} / \mathrm{dl}$ & $4(13.33)$ & $2(6.67)$ & \\
\hline$>250 \mathrm{mg} / \mathrm{dl}$ & $2(6.67)$ & 17 (56.67) & \\
\hline
\end{tabular}

${ }^{\star \star} P<0.01$, highly significant.

Table 3 CURB-65 score in nondiabetic and diabetic patients

\begin{tabular}{|c|c|c|c|}
\hline & \multicolumn{2}{|c|}{ Groups } & \multirow{2}{*}{$\begin{array}{c}\chi^{2} \\
P \text { value }\end{array}$} \\
\hline & Nondiabetic & Diabetic & \\
\hline Confusion & $6(20.00)$ & 7 (23.33) & 0.754 \\
\hline Urea $>7 \mathrm{mmol} / \mathrm{l}$ & $13(43.33)$ & $14(46.67)$ & 0.795 \\
\hline$R R \geq 30$ & $9(30.00)$ & $14(46.67)$ & 0.184 \\
\hline $\mathrm{SBP}<90 \mathrm{mmHg}$ or $\mathrm{DBP} \leq 60 \mathrm{mmHg}$ & 0 & 0 & 0.00 \\
\hline Age $\geq 65$ years & 14 (46.67) & $16(53.33)$ & 0.606 \\
\hline
\end{tabular}

$\mathrm{DBP}$, diastolic blood pressure; RR, respiratory rate; SBP, systolic blood pressure.

Table 4 Outcomes in nondiabetic and diabetic patients with community-acquired pneumonia

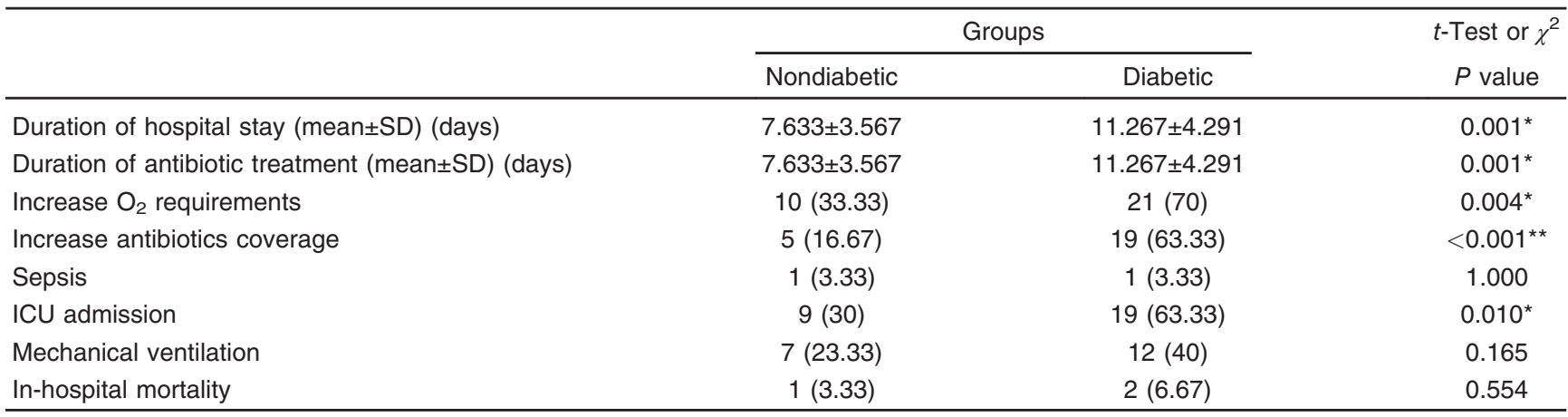

$\mathrm{O}_{2}$, oxygen. ${ }^{*} P \leq 0.05$, significant. ${ }^{*} P<0.01$, highly significant. 
Table 5 Comparison between different levels of admission blood glucose and community-acquired pneumonia patients' outcomes

\begin{tabular}{|c|c|c|c|c|c|}
\hline & \multicolumn{4}{|c|}{ Different levels of admission blood glucose } & \multirow{2}{*}{$\begin{array}{c}\text { ANOVA or } \\
\chi^{2} \\
P \text { value }\end{array}$} \\
\hline & $\begin{array}{l}<110 \mathrm{mg} / \mathrm{dl} \\
(N=4)\end{array}$ & $\begin{array}{c}110-199 \mathrm{mg} / \mathrm{dl} \\
(N=31)\end{array}$ & $\begin{array}{l}200-250 \mathrm{mg} / \mathrm{dl} \\
(N=6)\end{array}$ & $\begin{array}{l}>250 \mathrm{mg} / \mathrm{dll} \\
(N=19)\end{array}$ & \\
\hline Duration of hospital stay (mean \pm SD) (days) & $6.613 \pm 2.076$ & $6.613 \pm 2.076$ & $10.667 \pm 4.967$ & $13.211 \pm 3.614$ & $<0.001^{\star *}$ \\
\hline $\begin{array}{l}\text { Duration of antibiotic treatment }(\text { mean } \pm S D) \\
\text { (days) }\end{array}$ & $6.613 \pm 2.076$ & $6.613 \pm 2.076$ & $10.667 \pm 4.967$ & $13.211 \pm 3.614$ & $<0.001^{\star *}$ \\
\hline Increase in $\mathrm{O}_{2}$ requirements & 0 & $11(35.48)$ & $3(50.00)$ & $17(89.47)$ & $<0.001^{\star *}$ \\
\hline Increaseantibiotics coverage & 0 & $3(9.68)$ & $4(66.67)$ & $17(89.47)$ & $<0.001^{\star *}$ \\
\hline Sepsis & 0 & $1(3.23)$ & 0 & $1(5.26)$ & 0.904 \\
\hline ICU admission & 0 & $10(32.25)$ & $3(50.00)$ & $15(78.95)$ & $0.001^{*}$ \\
\hline Mechanical ventilation & 0 & $6(19.35)$ & $3(50.00)$ & $10(52.63)$ & 0.945 \\
\hline In-hospital mortality & 0 & 0 & $1(16.67)$ & $2(10.53)$ & 0.188 \\
\hline
\end{tabular}

ANOVA, analysis of variance; $\mathrm{O}_{2}$, oxygen. ${ }^{*} P \leq 0.05$, significant. ${ }^{* *} P<0.01$, highly significant.

duration of antibiotic treatment (13.211 \pm 3.614 days), increase in $\mathrm{O}_{2}$ requirements, increase antibiotic coverage, and ICU admission with an increase in CAP patients' blood glucose levels as shown in Table 5.

\section{Discussion}

Diabetes mellitus is a highly prevalent chronic metabolic disorder that is present in $\sim 5-10 \%$ of the elderly population, and it may be considered a risk factor for pneumonia [10]. Several investigations have found that CAP leads to an increase in the mortality rate among patients with diabetes more than that in patients without diabetes [11], whereas others have shown no association [12]. Thus, some studies have found that hyperglycemia on admission predicts poor outcomes in CAP [13], whereas others have not [14].

On the basis of the results of this study, on admission, CAP patients with increased blood glucose levels, either diabetic or nondiabetic, have adverse outcomes (Tables 4 and 5) even after adjusting for the other associated factors that may affect the prognosis for CAP such as age, sex, smoking habit, comorbidities (Table 1), and CURB-65 (Table 3).

Jensen et al. [15] studied the impact of admission blood glucose levels on the outcome of CAP in a hospital in their retrospective study, which was carried out on 1320 patients, and they found that that duration of hospital stay and antibiotic duration for diabetic patients were longer ( 6 days in diabetic patients and 5 days in nondiabetic patients), which was consistent with this study, as the duration of hospital stay and antibiotic duration for diabetic patients was 11 versus 7 days in nondiabetic patients.
Jensen et al. [15] also reported that the clinical course was more severe in nondiabetics and they explained that because diabetic patients were more adapted to have blood glucose levels elevated so they had less severe clinical course than nondiabetic patients, but this was not in agreement with this study and other previous studies $[13,16,17]$, which found that the increase in admission blood glucose was associated with a severe clinical course in diabetics.

McAlister et al. [5] also found that hyperglycemia on admission in patients with CAP mostly predicts adverse outcomes as for each $1-\mathrm{mmol} / 1$ increase in the blood glucose level, there was a $3 \%$ increase in the risk of in-hospital complications, and this finding was in agreement with ours.

Hyperglycemia on admission has been associated with increased mortality in various studies $[5,13,17]$, but this was not in agreement with this study as the inhospital mortality was insignificant (only two diabetic patients and one nondiabetic patient), and this can be explained by the small sample size and assessment of in-hospital mortality only without follow-up of the patients after discharge.

This study has its limitations. The sample was too small and hence we could not detect the difference in the mortality rate between diabetic and nondiabetic patients and we did not follow-up the patients after discharge to detect long-term mortality as we focused on in-hospital mortality.

\section{Conclusion}

On admission, CAP patients with increased blood glucose levels, either diabetic or nondiabetic, are expected to have poor outcomes. 


\section{Financial support and sponsorship}

Nil.

\section{Conflicts of interest}

There are no conflicts of interest.

\section{References}

1 Mahendra M, Jayaraj B, Limaye S, Chaya S, Dhar R, Mahesh P. Factors influencing severity of community-acquired pneumonia. Lung India 2018; 35:284-289.

2 Delamaire M, Maugendre D, Moreno M, Le Goff MC, Allannic H, Genetet B. Impaired leucocyte functions in diabetic patients. Diabet Med 1997; 14:29-34.

3 Liberatore R, Barbosa S, Alkimin M, Bellinati-Pires R, Florido M, Isaac L, et al. Is immunity in diabetic patients influencing the susceptibility to infections immunoglobulins, complement and phagocytic function in children and adolescents with type 1 diabetes mellitus. Pediat Diabetes 2005; 6:206-212.

4 Marik P, Bellomo R. Stress hyperglycemia: an essential survival response. Crit Care 2013; 17:305

5 McAlister F, Majumdar S, Blitz S, Rowe B, Romney J, Marrie T. The relation between hyperglycemia and outcomes in 2,471 patients admitted to the hospital with community-acquired pneumonia. Diabetes Care 2005; 28:810-815

6 Shah B, Hux J. Quantifying the risk of infectious diseases for people with diabetes. Diabetes Care 2003; 26:510-513.

7 Lionel A, Richard G, Antonio A, John G, Douglas C, Nathan C, et al. Infectious Diseases Society of America/American Thoracic Society Consensus Guidelines on the Management of Community-Acquired Pneumonia in Adults. Clin Infect Dis 2007; 44:S27-S72.
8 Lim W, van der Eerden M, Laing R, Boersma W, Karalus N, Town G, et al. Defining community acquired pneumonia severity on presentation to hospital: an international derivation and validation study. Thorax 2003 58:377-382.

9 Pickering D, Marsden J. How to measure blood glucose. Community Eye Health 2014; 87:56-57.

10 Ehrlich S, Quesenberry C, van Den Eeden K, Shan J, Ferrara A. Patients diagnosed with diabetes are at increased risk for asthma, chronic obstructive pulmonary disease, pulmonary fibrosis, and pneumonia but not lung cancer. Diabetes Care 2010; 33:55-60.

11 Falguera M, Pifarre R, Martin A, Sheikh A, Moreno A. Etiology and outcome of community-acquired pneumonia in patients with diabetes mellitus. Chest 2005; 28:3233-3239.

12 Shaw J, Sicree R, Zimmet P. Global estimates of the prevalence of diabetes for2010 and 2030. Diabetes Res Clin Pract 2010; 87:4-14.

13 Lepper P, Ott S, Nüesch E, von Eynatten M, Schumann C, Pletz MW, et al. Serum glucose levels for predicting death in patients admitted to hospital for community acquired pneumonia: prospective cohort study. BMJ 2012; 344:3397.

14 Eurich D, Gamble J, Marrie T, Majumdar S. Dysglycaemia and 90 day and 1 year risks of death or readmission in patients hospitalised for communityacquired pneumonia. Diabetologia 2010; 53:497-503.

15 Jensen A, Egelund G, Andersen S, Petersen P, Benfield T, FaurholtJepsen $\mathrm{D}$, et al. The impact of blood glucose on community-acquired pneumonia: a retrospective cohort study. ERJ Open Res 2017; 3:14-16.

16 Rueda AM, Ormond M, Gore M, Matloobi M, Giordano T, Musher D. Hyperglycemia in diabetics and non-diabetics: effect on the risk for and severity of pneumococcal pneumonia. J Infect 2010; 60:99-105.

17 Schuetz P, Friedli N, Grolimund E, Kut zA, Haubitz S, Christ-Crain M, et al. Effect of hyperglycaemia on inflammatory and stress responses and clinical outcome of pneumonia in non-critical-care inpatients: results from an observational cohort study. Diabetologia 2014; 57:275-284. 